\title{
Análise da rugosidade superficial de barras de aço SAE 1045 após torneamento
}

\section{Surface roughness analyses of $0.45 \% \mathrm{C}$ (SAE 1045) steel bars after turning}

Guilherme Roberto dos Santos Biasibetti ${ }^{1}$, Rafael Menezes Nunes ${ }^{1}$, Luiz Carlos de Cesaro Cavaler ${ }^{2}$, Alexandre da Silva Rocha ${ }^{1}$

\author{
${ }^{1}$ Laboratório de Transformação Mecânica - LdTM/CT/UFRGS, Av. Bento Gonçalves, 9500, CEP: 91501970, Porto \\ Alegre, Rio Grande do Sul, Brasil. \\ ${ }^{2}$ Laboratório de Manufatura Mecânica - LAMAM/SATC, Rua Pascoal Meller 73, CEP: 88805380, Criciúma, Santa \\ Catarina, Brasil. \\ e-mail: guilherme.roberto@ufrgs.br, rafael.nunes@ufrgs.br, alexandre.rocha@ufrgs.br, luiz.cavaler@satc.edu.br
}

\begin{abstract}
RESUMO
Neste trabalho foram investigadas as influências de alguns dos principais fatores do torneamento sobre o acabamento da superfície e a rugosidade de uma peça torneada. Foram analisadas barras de aço SAE 1045 torneadas em um torno controle numérico computadorizado (CNC), com auxílio da técnica de Planejamento de experimentos (DOE) para formar trinta e duas diferentes combinações de fatores, analisar suas interações e sua influência no acabamento de cada amostra. Os fatores de usinagem investigados foram: (1) avanço, (2) velocidade de corte, (3) raio de quina, (4) ângulo de saída e (5) região de medição da rugosidade. Por meio do DOE foram realizadas duas análises fatoriais: a primeira avaliou a influência dos cinco fatores na rugosidade média, representada por $\mathrm{R}_{\mathrm{a}}$, e a segunda avaliou a eficácia de cada conjunto de fatores em obter o acabamento alvo. Para isso, foi criado um índice que relaciona a rugosidade teórica de cada processo com a rugosidade medida pelo rugosímetro. Os resultados mostraram que o avanço e o raio de quina possuem elevado efeito padronizado em ambas as análises. Porém, enquanto a aplicação de um menor avanço (ou maior raio de quina) produziu superfícies com baixa $R_{a}$, por outro lado também prejudicou a eficácia do torneamento, pois contribuiu para obtenção de uma rugosidade significativamente maior que a rugosidade teórica. Já o fator velocidade de corte foi benéfico ao processo em ambas as análises. Não foi encontrada relevância da região de medição da rugosidade sobre a rugosidade média, $\mathrm{R}_{\mathrm{a}}$.
\end{abstract}

Palavras-chave: Acabamento, rugosidade, torneamento, SAE 1045.

\section{ABSTRACT}

This paper investigated the influence of some of the main turning parameters in surface finish and roughness of turning samples. The $0.45 \% \mathrm{C}$ (SAE 1045) steel bars samples, turned on a CNC turning machine, were analyzed using Design of experiments (DOE) approach to produce a total of thirty-two parameters combination, analyze its interactions and influences in each sample's surface finish. Machining parameters investigated were: (1) feed rate, (2) cutting speed, (3) nose radius, (4) rake angle and (5) region of roughness measurement. Two factorial analyses were conducted through the DOE data. The first one evaluated the influence of those five parameters in the average roughness, represented by $\mathrm{R}_{\mathrm{a}}$, and the second one evaluated the accuracy of each parameters combination to achieve the expected surface finish. For this measurement, an index was created to compare the theoretical surface roughness of each process with the surface roughness measured by rugosimeter. Results showed that parameters as feed rate and nose radius have strong standardized effect in both factorial analysis. Results shown that reduction of the feed rate (or increase in nose radius) was able to produce lower roughness average $\left(\mathrm{R}_{\mathrm{a}}\right)$ but, on the other hand, it also contribute to generate a surface roughness significant higher than theoretical roughness. The increase in cutting speed was beneficial to both, achieving a lower roughness average and improving process accuracy. The region of roughness measurement was found not significant to influence the roughness average, $R_{a}$.

Keywords: Finish, roughness, turning, SAE 1045. 


\section{INTRODUÇÃO}

O controle da qualidade dos componentes mecânicos é fundamental para o sucesso de qualquer processo de manufatura. Especialmente em processos de acabamento, o controle de parâmetros como: rugosidade da superfície, variações geométricas e região termicamente afetada, entre outros, é essencial para garantir a integridade da superfície e o desempenho dos componentes [1]. Dentre os diversos métodos para avaliar a integridade de uma superfície a rugosidade é a mais largamente aplicada [2]. Em hastes de vedação a rugosidade é um fator crítico para garantir a estanqueidade do sistema. Seu papel é fundamental para evitar o vazamento de fluidos que causariam a falha do sistema ou mesmo a contaminação do meio ambiente [3]. Na produção de rolamentos estudos consistentes comparam as propriedades da superfície (rugosidade, tensões residuais e outras) e sua relação com a vida em fadiga desses produtos [4,5]. A rugosidade da superfície pode ser empregada como indicador primário de acabamento, pois reflete diretamente as condições de corte empregadas no processo de usinagem [6]. Os principais fatores e fenômenos que se manifestam durante o corte e influenciam na rugosidade do produto acabado estão demostrados na Figura 1.

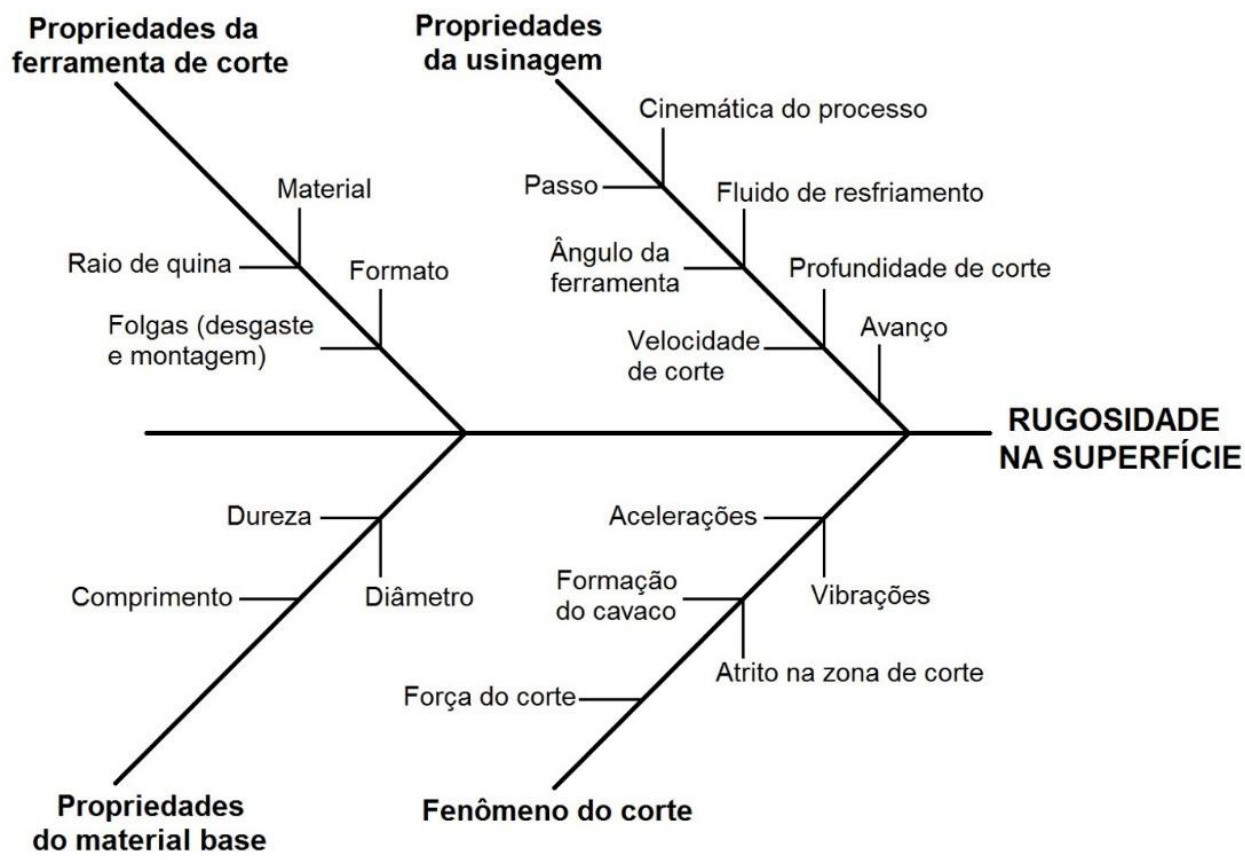

Figura 1: Fatores e fenômenos que se manifestam durante a usinagem e que resultam na rugosidade de uma superfície, adaptado de BENARDOS e VOSNIAKOS [6].

Naturalmente a rugosidade da superfície depende fortemente do processo, porém muitas vezes sua previsão direta pode ser quase impossível. A estratégia mais comum envolve a seleção de parâmetros de processo conservadores que não garantem a obtenção de um acabamento excelente tampouco a maximização da taxa de remoção de material [6]. Dentre os principais fatores que influenciam a rugosidade do processo se encontram condições de atrito, formação de gume postiço e desgaste da ferramenta [7]. Outros fatores que podem influenciar a rugosidade são a ocorrência de vibrações entre a ferramenta de corte e o material sendo torneado e principalmente vibrações do tipo chatter [8]. A velocidade de corte e o avanço são os dois parâmetros mais importantes que podem ser ajustados pelo operador para otimizar a condição de corte. A profundidade de corte é normalmente relativa ao diâmetro inicial e final da barra. O desempenho da ferramenta de corte depende em grande parte de sua precisão dimensional e de sua geometria. Por melhor que seja o material da ferramenta, se sua geometria não for adequada não haverá êxito na operação. O ângulo de incidência, raio de quina, a união entre ambos e suas faces são exemplos de elementos críticos da ferramenta [9]. O objetivo de uma engenharia de elevada qualidade é construir produtos, ou planejar rotas de produção, capazes de mitigar as principais fontes de erros e, dessa maneira, a etapa mais importante de um trabalho científico se encontra no planejamento do experimento e na seleção dos fatores de controle $[10,11]$.

Este trabalho tem como objetivo avaliar como alguns dos principais fatores do torneamento influenci- 
am na rugosidade superficial das amostras. E ainda comparar tanto a qualidade das diferentes superfícies criadas de forma qualitativa bem como investigar de forma quantitativa qual combinação de fatores favorecem a obtenção de uma rugosidade de processo mais próxima da rugosidade teórica.

\section{MATERIAIS E MÉTODOS}

\subsection{Planejamento do experimento (DOE)}

O experimento foi planejado de forma a utilizar a análise fatorial completa para avaliar como os fatores em estudo influenciaram na rugosidade das barras torneadas. Os quatro fatores de usinagem e propriedades da ferramenta de corte estudados neste experimento foram: (1) ângulo de saída $\gamma$, (2) raio de quina $r_{\varepsilon}$, (3) velocidade de corte $v_{c}$ e (4) avanço f. A escolha dos fatores investigados ocorreu através da revisão de trabalhos que citaram estes quatro fatores como fortemente responsáveis pela integridade da superfície, em especial a rugosidade, de ligas metálicas como o aço $\mathrm{SAE} 1045$ [12, 13, 14, 15, 16, 17, 18, 19]. O quinto parâmetro explorado no DOE foi a região de medição da rugosidade, ou posição axial, e está detalhado na seção 2.4.

Para elaboração da matriz do experimento fatorial foi atribuído a cada um dos fatores em estudo dois valores diferentes sendo um designado como alto (+1) e outro como baixo (-1). A Tabela 1 apresenta os fatores estudados neste trabalho e os valores assumidos para cada um deles. Desta maneira foi obtido o total de trinta e duas diferentes combinações.

Tabela 1: Fatores em estudos e grandezas utilizados na elaboração da matriz do DOE.

\begin{tabular}{c|c|c|c|c|c}
\hline FATORES & $\mathbf{v}_{\mathbf{c}}(\mathbf{m} / \mathbf{m i n})$ & $\mathbf{f}(\mathbf{m m} / \mathbf{r o t})$ & $\mathbf{r}_{\boldsymbol{\varepsilon}}(\mathbf{m m})$ & $\gamma\left(^{\circ}\right)$ & POSIÇÃO AXIAL \\
\hline-1 & 150 & 0,10 & 0,4 & +6 & Extremidade (I e III) \\
\hline+1 & 250 & 0,25 & 1,2 & -6 & Centro (II) \\
\hline
\end{tabular}

\subsection{Materiais}

O material utilizado neste trabalho foram barras de aço SAE 1045 produzidas pelo processo de trefilação combinada, recebidas com diâmetro de 20,65 mm e comprimento de $6 \mathrm{~m}$. Em laboratório, as barras longas foram cortadas com serra fita em amostras de $400 \mathrm{~mm}$ de comprimento cada. Descartou-se 0,40 m de cada extremidade das barras de $6 \mathrm{~m}$ por possuírem propriedades distintas do restante do material, conforme WAECHTER [20]. A composição química das amostras está apresentada na Tabela 2.

Tabela 2: Composição química das amostras de aço e norma SAE 1045 (em \%m/m), adaptado de NUNES [21].

\begin{tabular}{l|c|c|c|c|c|c|c|c|c}
\hline ELEMENTO & $\mathbf{C}$ & $\mathbf{S i}$ & $\mathbf{M n}$ & $\mathbf{P}$ & $\mathbf{S}$ & $\mathbf{C r}$ & $\mathbf{N i}$ & $\mathbf{M o}$ & $\mathbf{F e}$ \\
\hline AMOSTRA & 0,43 & 0,24 & 0,79 & 0,03 & 0,02 & 0,13 & 0,08 & 0,03 & Balanço \\
\hline NORMA (SAE) & $0,43-0,5$ & - & $0,6-0,9$ & $<0,04$ & $<0,05$ & - & - & - & Balanço \\
\hline
\end{tabular}

\subsection{Usinagem}

As barras foram submetidas a processo de torneamento em um torno CNC Romi 30D. As características distintas das ferramentas de corte $\left(\gamma_{\mathrm{n}}\right.$ e $\left.\lambda_{\mathrm{s}}\right)$ e outros ângulos relevantes que permaneceram constantes $\left(\kappa_{\mathrm{r}}, \kappa_{\mathrm{r}}\right.$ ' e $\left.\alpha_{\mathrm{n}}\right)$ estão apresentados na Figura 2. A usinagem foi realizada com dois passes, sendo o primeiro com profundidade de corte $\left(\mathrm{a}_{\mathrm{p}}\right)$ de $0,4 \mathrm{~mm}$, com o objetivo de remover qualquer heterogeneidade presente na superfície das barras, e o segundo passe de $0,1 \mathrm{~mm}$ que produziu a superfície analisada neste estudo. As barras foram usinadas a seco e a força aplicada no contraponto foi constante. 

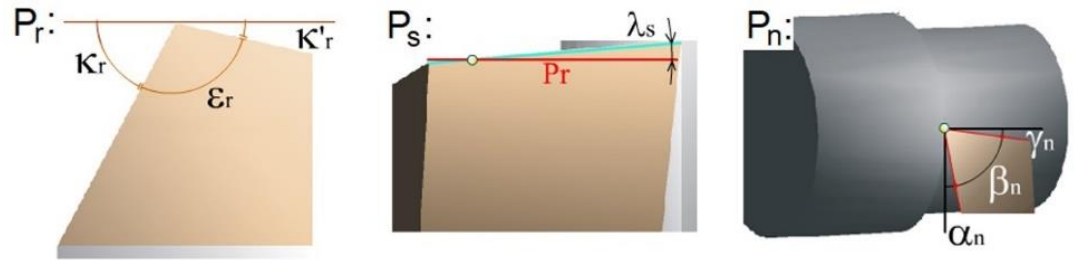

Figura 2: Definição das características geométricas das ferramentas de corte em seus principais planos: $\mathrm{P}_{\mathrm{r}}$, plano de referência; $\mathrm{P}_{\mathrm{s}}$, plano do gume; $\mathrm{P}_{\mathrm{n}}$, plano normal ao gume. Adaptado de CIMM [22].

Na Tabela 3 são mostradas as especificações técnicas das ferramentas de corte em conjunto com o suporte MTJNR/W utilizados para se obter as condições propostas no DOE. Foi utilizado o mesmo suporte em todas as operações de usinagem.

Tabela 3: Especificações e principais características das ferramentas de corte e suporte utilizados.

\begin{tabular}{c|c|c|c|c}
\hline $\begin{array}{c}\text { CÓDIGO DA } \\
\text { FERRAMENTA }\end{array}$ & $\begin{array}{c}\text { TNMG } \\
\mathbf{1 6 0 4 0 4 - T F}\end{array}$ & $\begin{array}{c}\text { TNMG } \\
\mathbf{1 6 0 4 1 2 - T F}\end{array}$ & $\begin{array}{c}\text { TNMA } \\
\mathbf{1 6 0 4 0 4}\end{array}$ & $\begin{array}{c}\text { TNMA } \\
\mathbf{1 6 0 4 1 2}\end{array}$ \\
\hline $\mathbf{r}_{\boldsymbol{\varepsilon}}(\mathbf{m m})$ & 0,4 & 1,2 & 0,4 & 1,2 \\
\hline $\boldsymbol{\lambda}_{\mathbf{s}}\left(^{\circ}\right)$ & 7 & 7 & -6 & -6 \\
\hline $\boldsymbol{\gamma}_{\mathbf{n}}\left(^{\circ}\right)$ & 7 & 7 & -6 & -6 \\
\hline $\boldsymbol{\kappa}_{\mathbf{r}}\left({ }^{\circ}\right)$ & 93 & 93 & 93 & 93 \\
\hline $\boldsymbol{\kappa}_{\mathbf{r}}\left(^{\circ}\right)$ & 27 & 27 & 27 & 27 \\
\hline $\boldsymbol{\alpha}_{\mathbf{n}}\left({ }^{\circ}\right)$ & 6 & 6 & 6 & 6 \\
\hline
\end{tabular}

As barras foram fixadas na placa de castanha de forma a deixar $200 \mathrm{~mm}$ entre a extremidade das castanhas e o contraponto. Foram realizadas duas etapas de usinagem para usinar cada uma das barras, ou seja, para cada barra de $400 \mathrm{~mm}$ de comprimento foram obtidas duas amostras de barras usinadas com o mesmo conjunto de fatores e com $200 \mathrm{~mm}$ cada, sendo uma denominada amostra 'a' e a outra amostra 'b', conforme Figura 3.

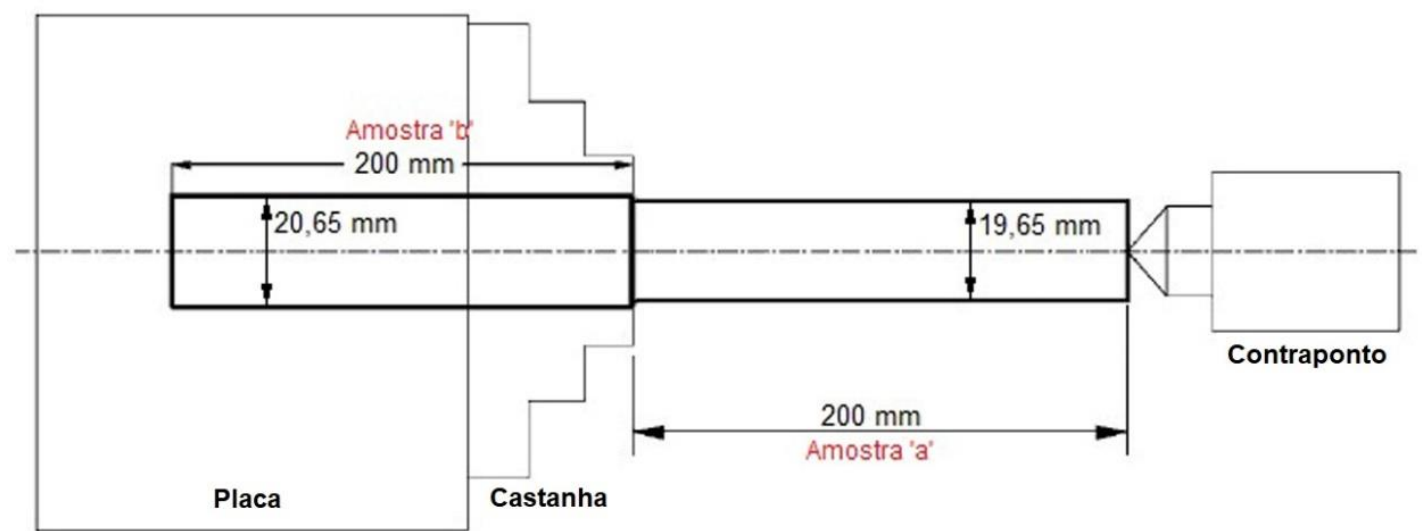

Figura 3: Configuração de montagem da barra a ser usinada, placa de castanha e contraponto identificando a diferenciação entre a amostra "a" e amostra "b", usinadas com os mesmos conjuntos de fatores.

\subsection{Análise da rugosidade}

A leitura da rugosidade das barras foi feita com rugosímetro portátil Mitutoyo SJ-210. Com o objetivo de obter um sistema estável para realizar a medição da rugosidade, a barra foi posicionada sobre uma base metálica com formato de cunha e o rugosímetro foi posicionado sobre a barra. A rugosidade foi medida em três posições axiais distintas de cada amostra: (I) próximo à placa castanha, (II) centro da barra, (III) próximo ao contraponto, Figura 4. 


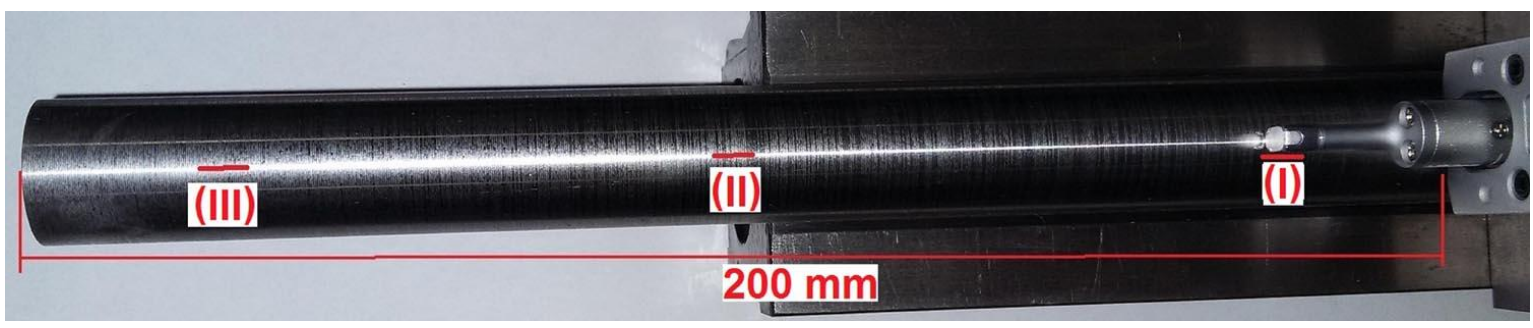

Figura 4: Posições de leitura da rugosidade para cada amostra.

Cada leitura avaliou os parâmetros de rugosidade média $\left(\mathrm{R}_{\mathrm{a}}\right)$, que corresponde à média aritmética dos valores absolutos dos afastamentos dos pontos do perfil de rugosidade, em relação à linha média, dentro do percurso de medição $\mathrm{L}_{m}$ e por esta razão possuiu pouca diferenciação entre picos ou vales que se encontram abaixo da linha média; como também a rugosidade média das máximas parciais $\left(\mathrm{R}_{\mathrm{z}}\right)$ que é definida como a soma dos valores absolutos dos pontos de maiores afastamentos (acima e abaixo da linha média). Graficamente, esse valor representa a altura entre os pontos máximo e mínimo do perfil e por esta razão se assemelha com a rugosidade teórica. Outros parâmetros relevantes na análise de rugosidade foram mantidos constantes em todas as análises e estão apresentados na Tabela 4.

Tabela 4: Parâmetros de leitura do rugosímetro.

\begin{tabular}{l|c}
\hline PARÂMETRO & VALOR \\
\hline Percurso de medição $\left(l_{\mathrm{m}}\right)$ & $4 \mathrm{~mm}$ \\
\hline Número de amostragens & 5 \\
\hline Comprimento de amostragem $\left(\mathrm{l}_{\mathrm{e}}\right)$ & $0,8 \mathrm{~mm}$ \\
\hline Cut-off & $0,8 \mathrm{~mm}$ \\
\hline
\end{tabular}

\section{RESULTADOS}

\subsection{Uniformidade da superfície usinada}

Após usinagem as barras foram inspecionadas visualmente e foi possível separá-las em quatro diferentes grupos de acordo com o acabamento obtido (Tabela 5).

Tabela 5: Segregação das amostras em grupos de acordo com o resultado das inspeções visuais.

\begin{tabular}{l|l|l}
\hline NOME DO GRUPO & SIGLA & BARRAS NO GRUPO \\
\hline Regular liso & RL & 3a, 3b, 8a, 8b, 11a, 11b, 16a, 16b \\
\hline Regular grosseiro & RG & 2a, 2b, 4a, 4b, 10a, 10b, 12a, 12b, 14a, 14b \\
\hline Irregular grosseiro & IG & 1a, 1b, 5a, 5b, 6a, 6b, 9a, 9b, 13a, 13b \\
\hline Variação axial de rugosidade & VA & 7a, 7b, 15a, 15b \\
\hline
\end{tabular}

\subsubsection{Grupo regular liso $(R L)$ e regular grosseiro $(R G)$}

As amostras presentes nesses dois grupos apresentaram rugosidade equivalente nas três regiões (I, II e III) e apresentaram um perfil da leitura do rugosímetro com as linhas do avanço bem definidas e repetições regulares. Na Figura 5 está apresentada a inspeção visual das barras do grupo RL nas quais foi observado um acabamento liso, e a Figura 6 apresenta a inspeção visual das barras do grupo RG nas quais é possível identificar as linhas do avanço e sua regularidade. 


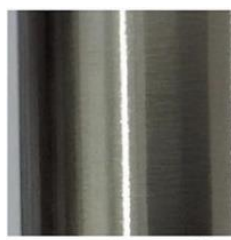

Barra 03a

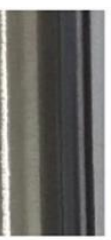

Figura 5: Inspeção visual de uma seção representativa da superfície das barras do grupo RL.

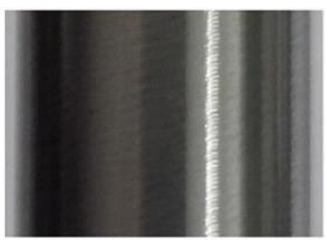

Barra 08a

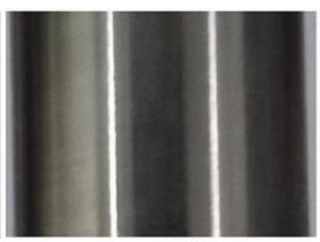

Barra 11a

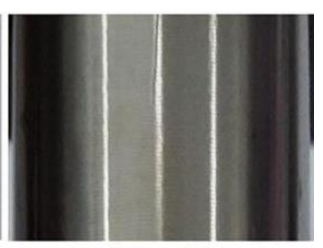

Barra $16 a$

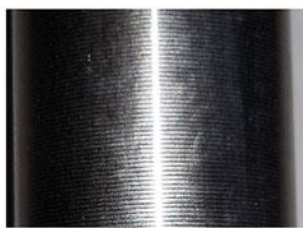

Barra 02a

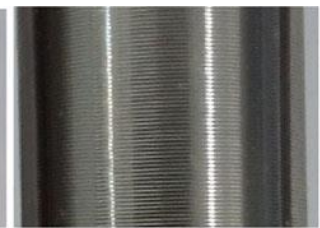

Barra 04a

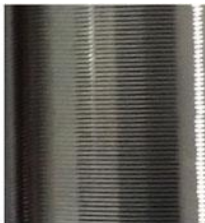

Barra 10a

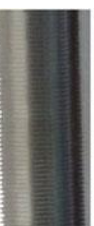

(0a

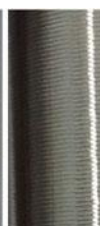

Barra 12a

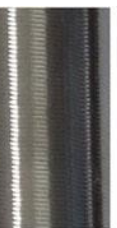

Figura 6: Inspeção visual de uma seção representativa da superfície das barras do grupo RG.

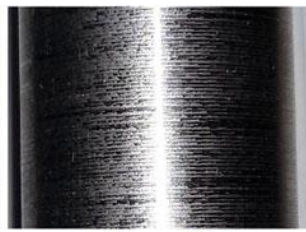

Barra 14a

A leitura da rugosidade produzida pelo rugosímetro para a amostra 03a, que foi usinada com um avanço de $0,10 \mathrm{~mm} / \mathrm{rev}$ e foi alocada no grupo RL, na Figura 7 e a leitura da amostra 02a, que foi usinada com um avanço de $0,25 \mathrm{~mm} / \mathrm{rev}$ e foi alocada no grupo RG, está apresentada na Figura 8. Em ambos os gráficos é possível confirmar a regularidade dos picos e vales e sua coerência com o avanço utilizado na usinagem.

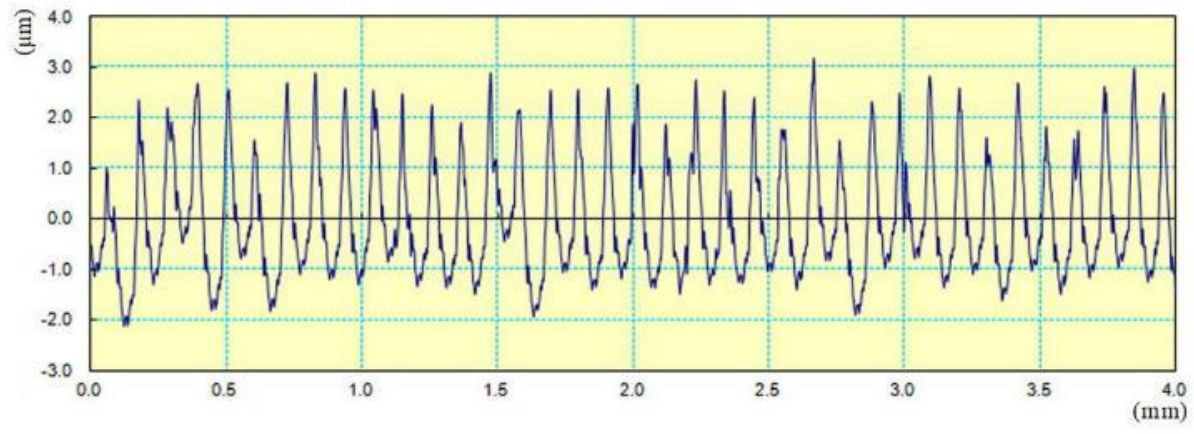

Figura 7: Perfil de rugosidade da barra 03a pertencente ao grupo regular liso.

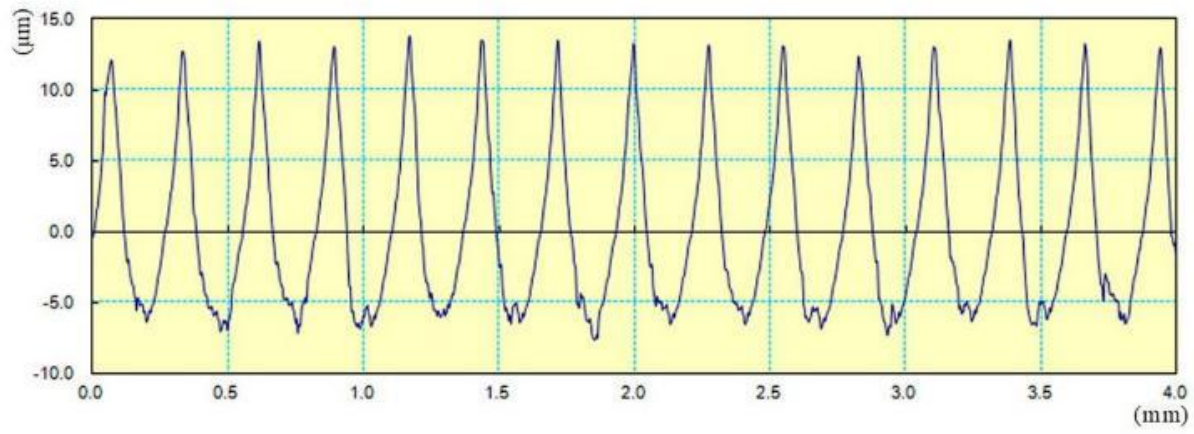

Figura 8: Perfil de rugosidade da barra 02a pertencente ao grupo regular grosseiro.

\subsubsection{Grupo irregular grosseiro (IG)}

No grupo IG foram agrupadas amostras que apresentaram uma rugosidade equivalente nas três regiões (I, II e III) e que, apesar de possuírem uma rugosidade visível, ela não apresentou repetibilidade ao longo da barra, conforme apresentado na Figura 9 pela inspeção visual. Apesar da rugosidade equivalente nas três regiões, foi encontrado um perfil irregular, conforme Figura 10. 


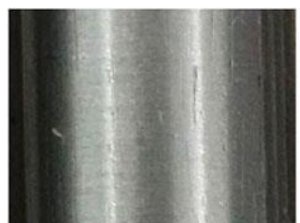

Barra 01a

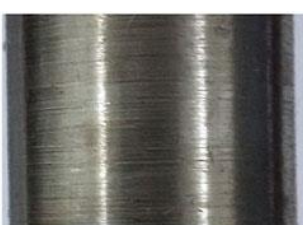

Barra 05a

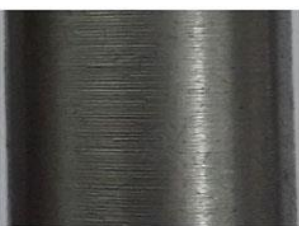

Barra 06a

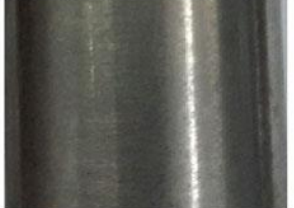

Barra 09a

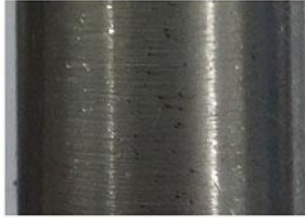

Barra 13a

Figura 9: Inspeção visual de uma seção representativa da superfície das barras do grupo IG.

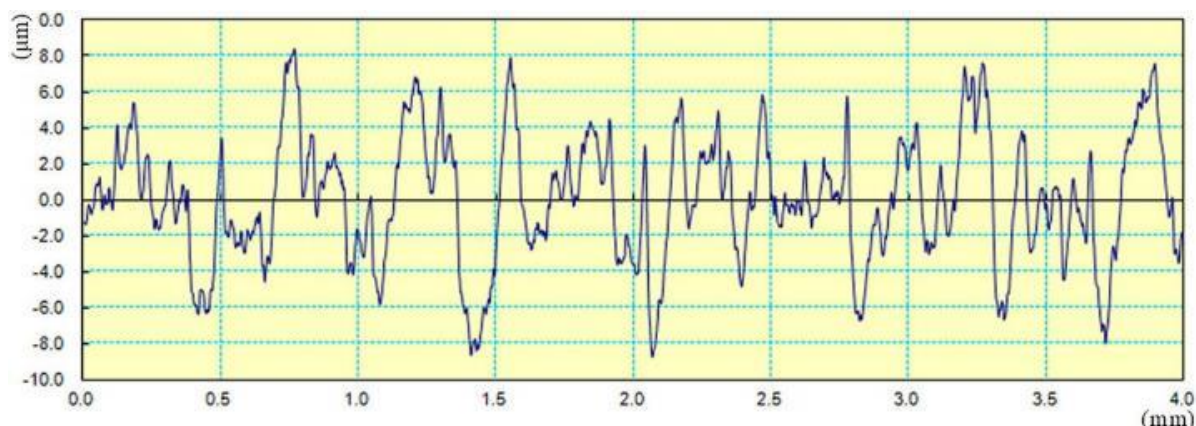

Figura 10: Perfil de rugosidade da barra 13a, típico para as amostras do grupo IG.

\subsubsection{Grupo variação axial de rugosidade (VA)}

No grupo VA se encontram amostras nas quais foram observados padrões de rugosidade diferentes ao longo da barra. Na Figura 11 foi apresentada uma região próxima ao contraponto ( 0 a $20 \mathrm{~mm}$ da extremidade) que apresentou um acabamento liso quando comparado a uma região próxima ao centro da barra (90 a $110 \mathrm{~mm}$ da extremidade) que apresentou um acabamento grosseiro.

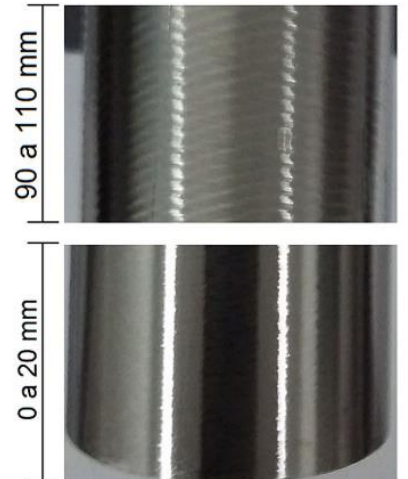

Barra 07a
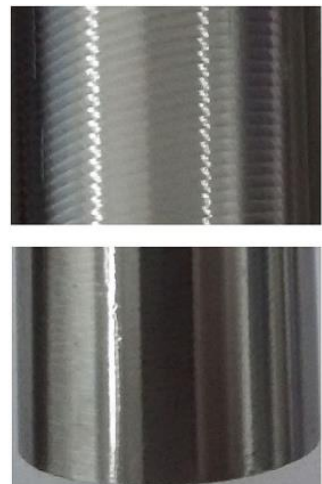

Barra 15a

Figura 11: Inspeção visual de uma seção representativa da superfície das barras do grupo VA.

As leituras de rugosidade realizadas com o rugosímetro na barra 15a confirmaram que a superfície da amostra possui acabamento diferenciado em função da posição axial da medida. A leitura realizada em uma região próxima ao contraponto (região I) encontrou superfície com apenas um padrão de repetição, com amplitude $\left(\mathrm{R}_{\mathrm{t}}\right)$ aproximadamente $3,5 \mu \mathrm{m}$ e período de $0,1 \mathrm{~mm}$ (o avanço utilizado nesta amostra foi de 0,1 $\mathrm{mm} / \mathrm{rev}$ ), Figura 12. Já a leitura realizada próximo ao centro da barra, região II, mostrou um padrão de repetição duplo, no período de $0,1 \mathrm{~mm}$ observou-se uma amplitude $\left(\mathrm{R}_{\mathrm{t}}\right)$ similar a anterior, aproximadamente $2 \mu \mathrm{m}$, enquanto que no período de $0,8 \mathrm{~mm}$ observou-se amplitude $\left(\mathrm{R}_{\mathrm{t}}\right)$ de $13 \mu \mathrm{m}$, Figura 13. 


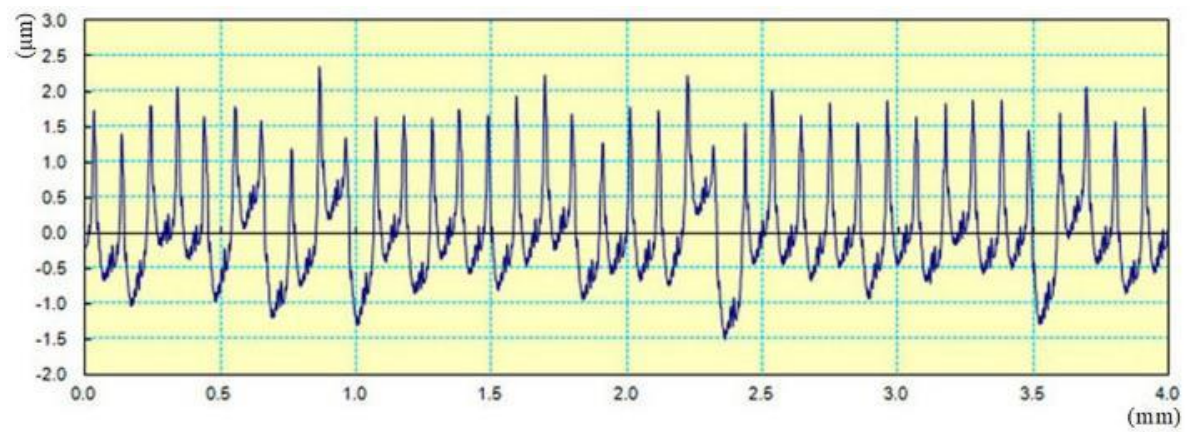

Figura 12: Perfil de rugosidade da barra 15a medida próximo ao contraponto, região I.

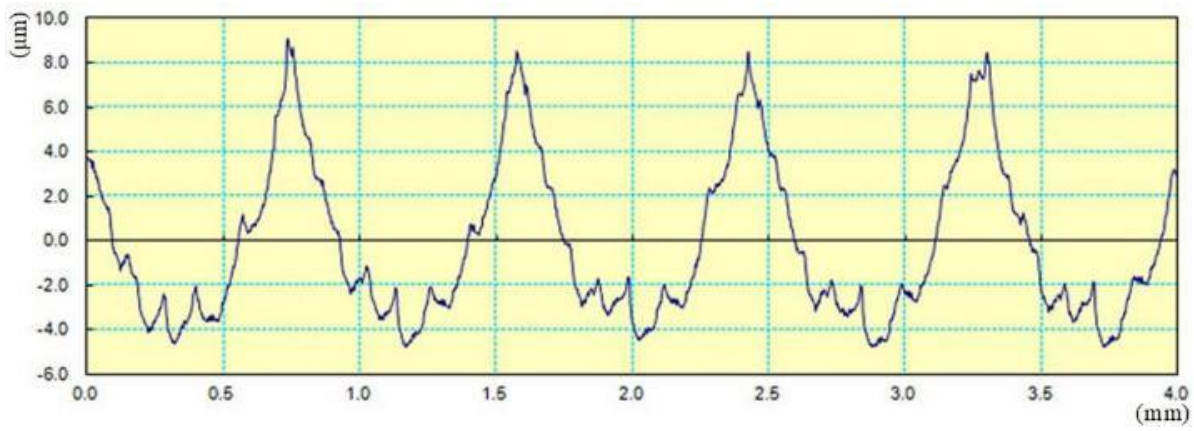

Figura 13: Perfil de rugosidade da barra 15a medida próximo ao centro da barra, região II.

\subsection{Influência dos fatores na rugosidade}

O DOE com cinco fatores e uma saída (média das rugosidades $\mathrm{R}_{\mathrm{a}}$ ) está apresentado na Tabela 6. A rugosidade nas diferentes regiões foi obtida a partir do cálculo da média das rugosidades medidas nas amostras com sufixo 'a' e 'b' e regiões similares, isto é, para o cálculo da média das rugosidades nas extremidades foi utilizada a Equação 1 e para o centro das barras foi utilizada a Equação 2.

$$
\begin{aligned}
& R_{a ; \text { barra } 01 ; \text { extremidades }}=\left(R_{a ; 01 a ; I}+R_{a ; 01 a ; I I I}+R_{a ; 01 b ; I}+R_{a ; 01 b ; I}\right) / 4 \\
& R_{a ; \text { barra } 01 ; \text { centro }}=\left(R_{a ; 01 a ; I I}+R_{a ; 01 b ; I I}\right) / 2
\end{aligned}
$$


Tabela 6: Matriz dos dados do DOE com cinco fatores e como saída a rugosidade média $\mathrm{R}_{\mathrm{a}}$.

\begin{tabular}{c|c|c|c|c|c|c}
\hline $\begin{array}{c}\text { BARRA } \\
(\mathbf{N} 0)\end{array}$ & $\begin{array}{c}\text { ÂNGULO DE } \\
\text { SAÍDA }\left(^{\circ}\right)\end{array}$ & $\begin{array}{c}\text { RAIO DE } \\
\text { QUINA }(\mathbf{m m})\end{array}$ & $\begin{array}{c}\text { VELOCIDADE DE } \\
\text { CORTE }(\mathbf{m} / \mathbf{m i n})\end{array}$ & $\begin{array}{c}\text { AVANÇO } \\
(\mathbf{m m} / \mathbf{r o t})\end{array}$ & $\begin{array}{c}\text { Ra }(\boldsymbol{\mu m}) \\
\text { CENTRO }\end{array}$ & $\begin{array}{c}\text { Ra }(\boldsymbol{\mu m}) \\
\text { EXTREMIDADE }\end{array}$ \\
\hline $\mathbf{1}$ & +6 & 0,4 & 150 & 0,10 & 2,546 & 2,154 \\
\hline $\mathbf{2}$ & +6 & 0,4 & 150 & 0,25 & 4,960 & 4,961 \\
\hline $\mathbf{3}$ & +6 & 0,4 & 250 & 0,10 & 0,976 & 0,985 \\
\hline $\mathbf{4}$ & +6 & 0,4 & 250 & 0,25 & 4,902 & 4,894 \\
\hline $\mathbf{5}$ & +6 & 1,2 & 150 & 0,10 & 3,553 & 3,562 \\
\hline $\mathbf{6}$ & +6 & 1,2 & 150 & 0,25 & 4,303 & 3,839 \\
\hline $\mathbf{7}$ & +6 & 1,2 & 250 & 0,10 & 2,043 & 1,535 \\
\hline $\mathbf{8}$ & +6 & 1,2 & 250 & 0,25 & 1,555 & 1,632 \\
\hline $\mathbf{9}$ & -6 & 0,4 & 150 & 0,10 & 2,028 & 2,161 \\
\hline $\mathbf{1 0}$ & -6 & 0,4 & 150 & 0,25 & 4,974 & 5,068 \\
\hline $\mathbf{1 1}$ & -6 & 0,4 & 250 & 0,10 & 1,420 & 1,356 \\
\hline $\mathbf{1 2}$ & -6 & 0,4 & 250 & 0,25 & 4,817 & 4,823 \\
\hline $\mathbf{1 3}$ & -6 & 1,2 & 150 & 0,10 & 2,682 & 2,953 \\
\hline $\mathbf{1 4}$ & -6 & 1,2 & 150 & 0,25 & 1,292 & 1,432 \\
\hline $\mathbf{1 5}$ & -6 & 1,2 & 250 & 0,10 & 3,016 & 1,090 \\
\hline $\mathbf{1 6}$ & -6 & 1,2 & 250 & 0,25 & 1,169 & 1,160 \\
\hline
\end{tabular}

A análise fatorial foi realizada a partir das informações consolidadas na Tabela 6. O gráfico de Pareto da Figura 14 mostra que o maior impacto sobre o resultado da rugosidade $\mathrm{R}_{\mathrm{a}}$ foi obtido para uma combinação de raio de quina $\left(r_{\varepsilon}\right)$ e avanço (f). Individualmente os fatores com maior influência sobre a rugosidade $R_{a}$ foram, respectivamente, avanço (f), raio de quina $\left(\mathrm{r}_{\varepsilon}\right)$, velocidade de corte $\left(\mathrm{v}_{\mathrm{c}}\right)$, ângulo de saída $(\gamma)$ e posição axial, cujo efeito padronizado ficou abaixo do ponto de corte, sinalizado pela linha pontilhada, e foi considerado não significante.

A análise conjunta do gráfico de Pareto, Figura 14, e do gráfico dos principais efeitos, Figura 15, mostra que no sentido do menor avanço e maior raio de quina foram encontradas as menores médias de $R_{a}$ e, ainda, que o aumento da velocidade de corte possui efeito de reduzir $R_{a}$ e que a sua influência foi quase tão intensa quanto o efeito do raio de quina. $\mathrm{O}$ ângulo de saída quando negativo $\left(-6^{\circ}\right)$ contribui para uma redução do $R_{a}$, porém esta contribuição foi apenas ligeiramente acima do limite da significância.

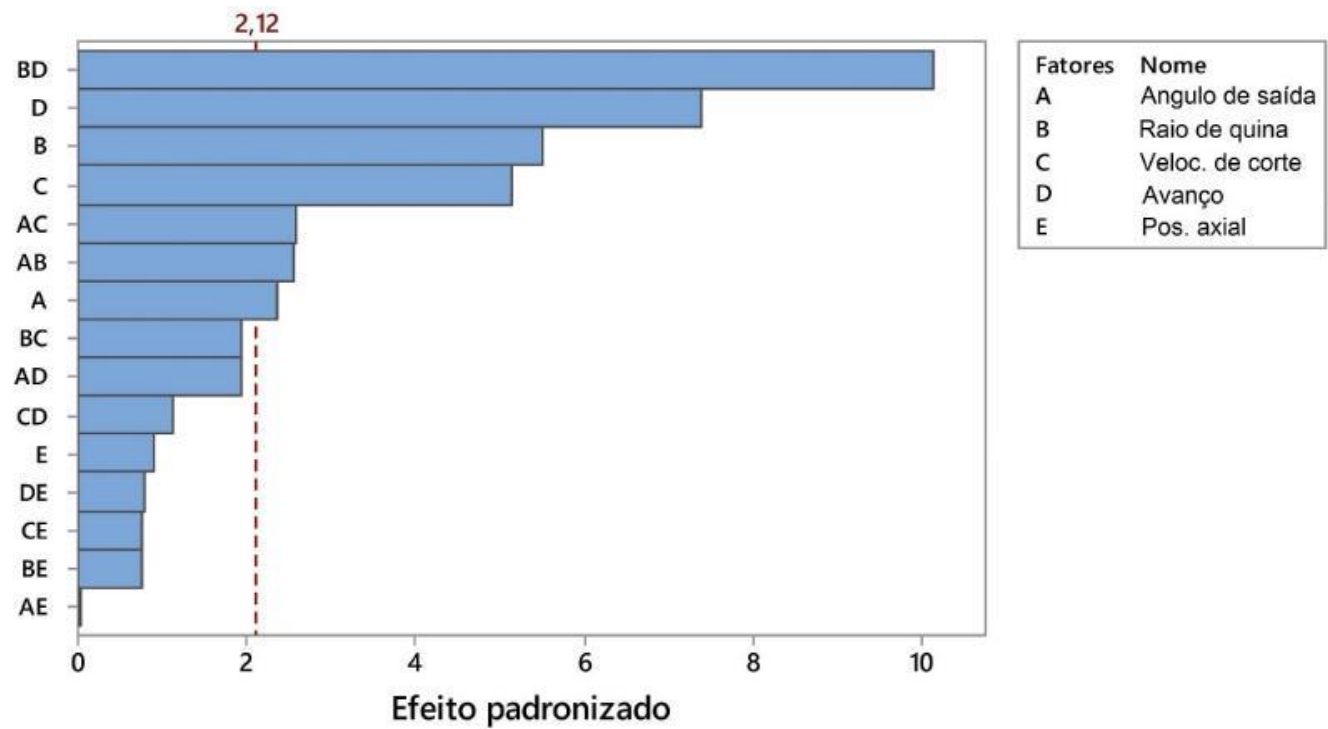

Figura 14: Gráfico de Pareto dos efeitos padronizados dos cinco fatores sobre a resposta de $\mathrm{R}_{\mathrm{a}}$, para $\alpha=0,05$. 


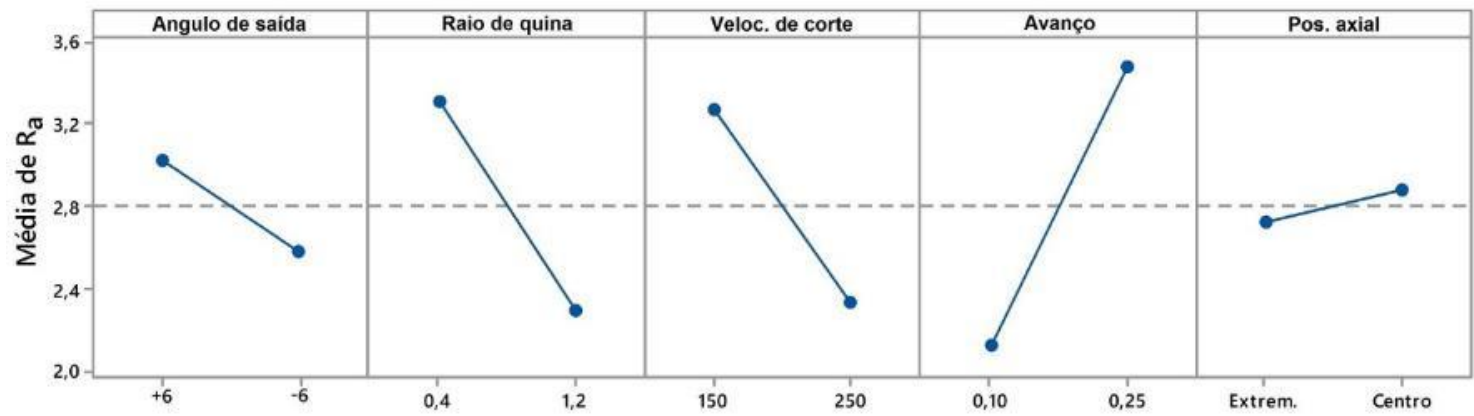

Figura 15: Gráficos dos principais efeitos dos cinco fatores sobre a rugosidade $\mathrm{R}_{\mathrm{a}}$.

\subsection{Eficácia do processo de torneamento}

A rugosidade teórica foi utilizada como referência para avaliar se o acabamento obtido no processo de usinagem de cada barra foi satisfatório. Para realizar essa análise foi utilizado um índice que relaciona a rugosidade teórica e a rugosidade obtida $\left(\mathrm{I}_{\mathrm{R}}\right)$. Este índice foi calculado através do produto da média das rugosidades máximas de uma dada amostra (obtido a partir do $\mathrm{R}_{\mathrm{Z} \text {;média }}$ ) e pela rugosidade teórica $\left(\mathrm{R}_{\mathrm{th}}\right)$, Equação 3 . Quando $\mathrm{I}_{\mathrm{R}}$ possui valores próximo a 1,0 indica a rugosidade obtida se aproxima significativamente da rugosidade teó-

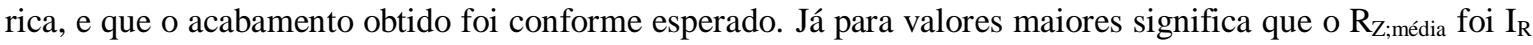
vezes maior que a $\mathrm{R}_{\mathrm{th}}$ indicando que o processo de torneamento deve ter sofrido influência de outros fatores que prejudicaram o acabamento.

$I_{R}=R_{Z ; \text { médial }} / R_{\text {th }}$

O parâmetro posição axial de medição da rugosidade mostrou não ser significativo, conforme análise do item anterior (3.2), por esta razão este parâmetro foi suprimido da análise seguinte. Deste modo o $\mathrm{R}_{\mathrm{Z} \text {;média }}$ foi calculado a partir da média aritmética das rugosidades $\mathrm{R}_{\mathrm{Z}}$ medidas nas três posições de cada barra e das amostras com sufixo $a$ e $b$, Equação 4. O R $\mathrm{R}_{\mathrm{th}}$, medida em $\mu \mathrm{m}$, de cada amostra foi obtido pela Equação 5 [7], que relaciona os fatores avanço ( $\mathrm{mm} /$ revolução) e raio de ponta $(\mathrm{mm})$.

$$
\begin{aligned}
& R_{Z ; m e ́ d i a}=\left(R_{z ; 01 a ; I}+R_{Z ; 01 a, I I}+R_{z ; 01 a, I I I}+R_{z ; 01 b ; I}+R_{Z ; 01 b ; I I}+R_{z ; 01 b ; I I I}\right) / 6 \\
& R_{t h}=\left(f^{2} .1000\right) /\left(\mathrm{r}_{\varepsilon} .8\right)
\end{aligned}
$$

Os fatores de usinagem de cada uma das dezesseis barras e as rugosidades, $\mathrm{R}_{\mathrm{Z} ; \text { média }}, \mathrm{R}_{\mathrm{th}}$, e o índice, $\mathrm{I}_{\mathrm{R}}$, foram consolidados na Tabela 7. Os dados apresentados nesta tabela foram utilizados para construir um experimento e análise fatorial para avaliar a influência dos fatores sobre $I_{R}$. 
Tabela 7: Matriz dos dados do DOE com quatro fatores como entrada e como saída o índice $I_{R}$, bem como os valores de RZ;média e Rth utilizados para o cálculo do índice.

\begin{tabular}{c|c|c|c|c|c|c|c|c}
\hline $\begin{array}{c}\text { BARRA } \\
\mathbf{( N o})\end{array}$ & $\begin{array}{c}\text { ÂNGULO DE } \\
\text { SAÍDA ( }{ }^{\circ}\end{array}$ & $\begin{array}{c}\text { RAIO DE } \\
\text { QUINA } \\
(\mathbf{m m})\end{array}$ & $\begin{array}{c}\text { VELOCIDADE } \\
\text { DE CORTE } \\
(\mathbf{m} / \mathbf{m i n})\end{array}$ & $\begin{array}{c}\text { AVANÇO } \\
(\mathbf{m m} / \mathbf{r o t})\end{array}$ & GRUPO & $\begin{array}{c}\mathbf{R}_{\mathbf{z} ; m \text { édia }} \\
(\boldsymbol{\mu m})\end{array}$ & $\mathbf{R}_{\text {th }}(\boldsymbol{\mu m})$ & $\mathbf{I}_{\mathbf{R}}$ \\
\hline $\mathbf{1}$ & +6 & 0,4 & 150 & 0,10 & IG & 12,062 & 3,125 & 3,86 \\
\hline $\mathbf{2}$ & +6 & 0,4 & 150 & 0,25 & RG & 20,958 & 19,531 & 1,07 \\
\hline $\mathbf{3}$ & +6 & 0,4 & 250 & 0,10 & RL & 5,525 & 3,125 & 1,77 \\
\hline $\mathbf{4}$ & +6 & 0,4 & 250 & 0,25 & RG & 20,449 & 19,531 & 1,05 \\
\hline $\mathbf{5}$ & +6 & 1,2 & 150 & 0,10 & IG & 18,292 & 1,042 & 17,56 \\
\hline $\mathbf{6}$ & +6 & 1,2 & 150 & 0,25 & IG & 19,592 & 6,510 & 3,01 \\
\hline $\mathbf{7}$ & +6 & 1,2 & 250 & 0,10 & VA & 8,788 & 1,042 & 8,44 \\
\hline $\mathbf{8}$ & +6 & 1,2 & 250 & 0,25 & RL & 8,066 & 6,510 & 1,24 \\
\hline $\mathbf{9}$ & -6 & 0,4 & 150 & 0,10 & IG & 12,181 & 3,125 & 3,90 \\
\hline $\mathbf{1 0}$ & -6 & 0,4 & 150 & 0,25 & RG & 19,810 & 19,531 & 1,01 \\
\hline $\mathbf{1 1}$ & -6 & 0,4 & 250 & 0,10 & RL & 6,990 & 3,125 & 2,24 \\
\hline $\mathbf{1 2}$ & -6 & 0,4 & 250 & 0,25 & RG & 19,195 & 19,531 & 0,98 \\
\hline $\mathbf{1 3}$ & -6 & 1,2 & 150 & 0,10 & IG & 15,096 & 1,042 & 14,49 \\
\hline $\mathbf{1 4}$ & -6 & 1,2 & 150 & 0,25 & RG & 8,226 & 6,510 & 1,26 \\
\hline $\mathbf{1 5}$ & -6 & 1,2 & 250 & 0,10 & VA & 8,605 & 1,042 & 8,26 \\
\hline $\mathbf{1 6}$ & -6 & 1,2 & 250 & 0,25 & RL & 6,614 & 6,510 & 1,02 \\
\hline
\end{tabular}

A análise de Pareto, Figura 16, mostra que as influências dos fatores de usinagem sobre o $\mathrm{I}_{\mathrm{R}}$, da maior influência para a menor, foram: avanço, raio de quina, combinação de avanço e raio de quina, velocidade de corte e na sequência demais combinações destes fatores. O ângulo de saída foi o parâmetro que individualmente possui a menor influência e seu efeito padronizado ficou abaixo do ponto de corte, podendo seu efeito ser considerado não significante.

$\mathrm{O}$ efeito do aumento de fatores como avanço e a velocidade de corte contribuíram para redução do $\mathrm{I}_{\mathrm{R}}$, enquanto que o aumento do raio de quina contribui para o aumento do $\mathrm{I}_{\mathrm{R}}$. $\mathrm{O}$ efeito individual dos fatores estudados foi apresentado na Figura 17.

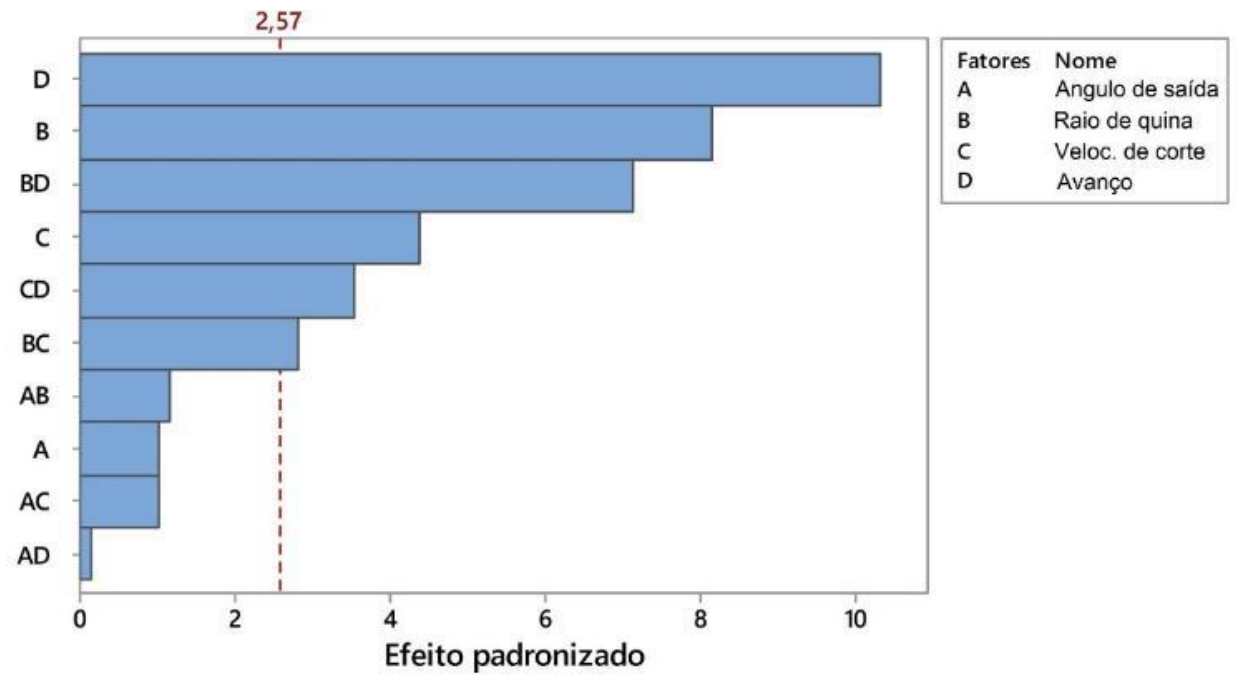

Figura 16: Gráfico de Pareto dos efeitos padronizados dos quatro fatores sobre o índice $I_{R}$, para $\alpha=0,05$. 


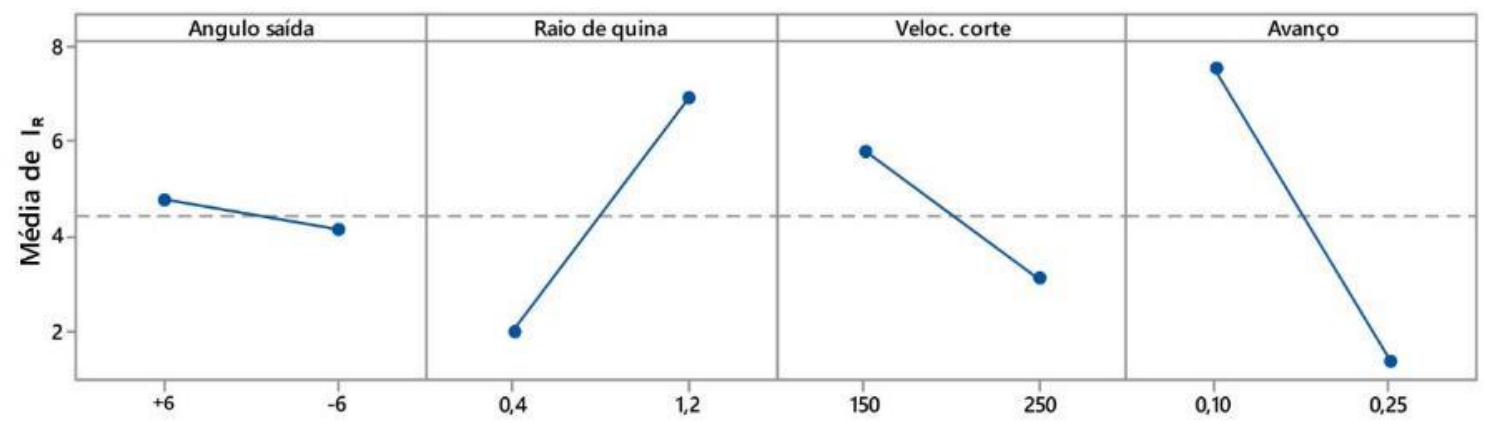

Figura 17: Gráficos dos principais efeitos dos quatro fatores sobre o índice $I_{R}$.

\section{DISCUSSÕES}

A separação das amostras por grupos se mostrou interessante para analisar os efeitos semelhantes que uma combinação adequada ou não de fatores de usinagem pode causar. Em especial as amostras 07 e 15 do grupo VA que apresentaram $I_{R}$ elevado, respectivamente 8,44 e 8,26, e que também apresentaram rugosidade média $\mathrm{R}_{\mathrm{a}}$ diferente ao longo do comprimento. As amostras do grupo IG apresentaram os maiores $\mathrm{I}_{\mathrm{R}}$, de 3,01 a 17,56, enquanto as amostras que visualmente apresentaram uma superfície regular (grupo RL e RG) tiveram uma variação do $I_{R}$ de 0,98 a 2,24. Esta análise permitiu identificar que os fenômenos de processo que prejudicam o acabamento das peças torneadas ocorreram na grande maioria dos processos, porém com magnitudes diferentes. E ainda, verifica-se que possivelmente existe um limite, no qual estes fenômenos comprometem a regularidade da superfície, sendo que nas análises realizadas esse limite se encontra entre o $\mathrm{I}_{\mathrm{R}}$ de 2,24 a 3,01. É provável que dentre as causas para a obtenção das superfícies irregulares se encontra a influência de vibrações de maior intensidade e caráter caótico, possivelmente vibrações do tipo chatter conforme descrito por TANSEL et al [23] e SIDDHPURA e PAUROBALLY [24].

\subsection{Posição axial}

As barras 07 e 15 foram usinadas com os mesmos fatores, com exceção do ângulo de saída da ferramenta de corte que foi $+6^{\circ}$ para a barra 07 e $-6^{\circ}$ para a barra 15 . É provável que o conjunto de fatores de usinagem aplicado no torneamento das duas barras resultaram em um modo de vibração específico. Esse modo de vibração deve possuir sua magnitude influenciada pela distância em relação à extremidade da barra, que sofre força de usinagem pela ferramenta de corte, e assim deu origem a um acabamento diferente nas amostras ao longo do seu comprimento.

Este acabamento só foi observado nas barras 07 e 15 indicando que este modo de vibração não ocorreu nas demais amostras. E ainda, conforme verificado pela análise fatorial e o gráfico de Pareto (Figura 14), a influência da posição axial de medição da rugosidade não foi significante. Sendo assim é seguro afirmar que para todas as demais amostras a rugosidade média não variou significativamente ao longo do seu comprimento.

\subsection{0 avanço}

Dentre os fatores de usinagem estudados, o avanço foi o parâmetro que individualmente mostrou maior influência tanto sobre $R_{a}$ quanto sobre $I_{R}$. A sua influência sobre $R_{a}$ pode ser prevista pela Equação 5 , que informa que a rugosidade teórica é proporcional ao quadrado do avanço $\left(\mathrm{R}_{\text {th }} \alpha \mathrm{f}^{2}\right)$, ou seja, em um processo de torneamento para se obter uma rugosidade baixa deve-se utilizar avanços pequenos. Este comportamento foi confirmado pelo gráfico dos principais efeitos do avanço sobre $\mathrm{R}_{\mathrm{a}}$, Figura 15 .

Por outro lado, avanços pequenos resultaram em um elevado $I_{R}$, conforme verificado na Figura 17, ou seja, ao aplicar um avanço pequeno com a intenção de obter uma baixa rugosidade foram criadas condições para que ocorressem fatores que resultaram em prejuízo na qualidade do acabamento. Segundo TRENT e WRIGHT [9], a redução do avanço no torneamento reduz a força contra a ferramenta de corte e em alguns casos pode comprometer a estabilidade do sistema e induzir vibrações, como resultado se observa redução da qualidade do acabamento. 
Desta maneira, por ser o parâmetro com efeito padronizado mais intenso e possuir efeito concorrente sobre $R_{a}$ e $I_{R}$, a escolha adequada do avanço se torna fundamental para o controle do acabamento da peça usinada, já que seu valor deve satisfazer o acabamento pretendido da peça, porém não deve comprometer a eficácia do processo de torneamento, induzindo um $\mathrm{I}_{\mathrm{R}}$ elevado.

$\mathrm{O}$ avanço também foi encontrado predominante sobre os demais fatores a respeito de sua influência sobre a rugosidade por CAPELLO [13] e MUÑOZ-ESCALONA e CASSIER [12]. Bem como foi encontrado por GUNNBERG et al [17], CAPELLO [13], MUÑOZ-ESCALONA e CASSIER [12], que é possível melhorar o acabamento de uma superfície usinada por torneamento, reduzindo sua rugosidade, a partir da redução do avanço e aumento do raio de quina e velocidade de corte.

\subsection{0 raio de quina}

É possível prever a influência do raio de quina sobre a rugosidade teórica pela Equação 5, sendo que este é inversamente proporcional a rugosidade teórica $\left(\mathrm{R}_{\mathrm{th}} \alpha 1 / \mathrm{r}_{\varepsilon}\right)$, ou seja, para obtenção de uma rugosidade teórica baixa se faz necessário utilizar um raio de quina alto. Este comportamento foi confirmado pelo gráfico dos principais efeitos do raio de quina sobre $\mathrm{R}_{\mathrm{a}}$, Figura 15 .

$O$ efeito do raio de quina sobre $I_{R}$ foi concorrente ao seu efeito sobre $R_{t h}$, ou seja, ao aumentarmos o raio de quina com o objetivo de reduzirmos a rugosidade teórica inevitavelmente temos como consequência um aumento no $I_{R}$ (Figura 17), que representa a obtenção de uma rugosidade $R_{Z}$ maior que a esperada. A abordagem indicada para determinação do raio de quina deve ser similar à adotada para o avanço.

\subsection{A velocidade de corte}

O cálculo da rugosidade teórica, Equação 5, não depende do termo velocidade de corte. Porém a partir da análise do gráfico de Pareto, Figura 14, é possível verificar que a velocidade de corte possui um efeito padronizado sobre a rugosidade $\mathrm{R}_{\mathrm{a}}$ quase tão intenso quanto o raio de quina. Os gráficos dos principais efeitos da velocidade de corte sobre $R_{a}$, Figura 15 , e sobre $I_{R}$, Figura 17, mostram que o aumento da velocidade de corte resultou na redução de ambos $R_{a}$ e $I_{R}$. Diferentemente do avanço e raio de quina, a manipulação da velocidade de corte no torneamento pode ser utilizada para obter simultaneamente uma redução do $I_{R}$ e da $R_{a}$.

Segundo FERRARESI [7], em velocidades de corte baixas ocorre a formação de uma aresta postiça de corte (ou gume postiço). O material depositado transitoriamente na superfície de saída da ferramenta tende a sair na forma de partículas que aderem tanto ao cavaco quanto a superfície usinada prejudicando sensivelmente o acabamento da superfície. Geralmente este problema pode ser amenizado com o aumento da temperatura do corte, que pode ser obtido através do aumento da velocidade de corte.

\subsection{0 ângulo de saída}

$\mathrm{O}$ ângulo de saída apresentou um efeito discreto sobre a rugosidade $\mathrm{R}_{\mathrm{a}}$, indicando que o ângulo de saída negativo $\left(-6^{\circ}\right)$ influenciou na obtenção de um melhor acabamento das amostras torneadas. Porém seu efeito padronizado foi apenas ligeiramente acima do limite de significância, conforme mostrado no gráfico de Pareto (Figura 14). Já para a análise do $I_{R}$ o ângulo de saída ficou abaixo do limite de significância, exposto no gráfico de Pareto (Figura 16).

É possível que os fatores escolhidos para análise do ângulo de saída estejam muito próximos e por esta razão não foi encontrada influência em sua mudança ou realmente o efeito padronizado do ângulo de saída sobre $\mathrm{R}_{\mathrm{a}}$ seja pequeno, quando comparado aos demais fatores em estudo, e sobre $\mathrm{I}_{\mathrm{R}}$ não seja significante.

\section{CONCLUSÕES}

A utilização do índice, $\mathrm{I}_{R}$, se mostrou competente para comparar a eficácia do acabamento no torneamento, pois relacionou a rugosidade alvo de cada processo $\left(R_{t h}\right)$ com a rugosidade obtida $\left(R_{Z ; m e ́ d i a ~}\right)$ e permitiu avaliar quais processos sofreram influência de fenômenos que contribuíram para um acabamento inferior ao esperado.

Em um processo no qual os fenômenos de vibração, ou outros fatores não desejados, foram minimiza- 
dos e se encontram sobre controle, o fator posição axial não deve influenciar na rugosidade e no acabamento da peça torneada.

Os fatores avanço e raio de quina mostraram possuir influência semelhante tanto sobre a rugosidade média $R_{a}$ quanto sobre o índice $I_{R}$. Ambos fatores apresentaram influência concorrente, isto é, quando um valor minimiza $R_{a}$ e $R_{\text {th }}$ inevitavelmente eleva o valor de $I_{R}$. Desta maneira a escolha do avanço e do raio de quina deve adotar um valor que se aproxime da $\mathrm{R}_{\text {th }}$ pretendida, porém que não comprometa a eficácia do torneamento resultando em um elevado $I_{R}$.

A velocidade de corte mostrou ser um parâmetro chave na obtenção de um ótimo acabamento no processo de torneamento, sendo possivelmente o mais importante dentre os fatores estudados. Apesar de seu efeito padronizado ser inferior ao do avanço e do raio de quina, a velocidade de corte foi o único parâmetro que influenciou simultaneamente a obtenção de um acabamento refinado, através da redução do $R_{a} e R_{t h}$, $e$ contribui para a redução do $I_{R}$.

$\mathrm{O}$ ângulo de saída foi o fator que apresentou o menor efeito sobre $\mathrm{R}_{\mathrm{a}}$ quando comparado com os demais fatores. Sua influência sobre a eficácia do acabamento, $I_{R}$, não foi significativo. Dentro da faixa de valores estudados, que foi - 6 e $6^{\circ}$, é possível afirmar que ângulo de saída não é um parâmetro crítico para o controle do acabamento no processo de torneamento.

\section{AGRADECIMENTOS}

Os autores agradecem a CAPES, CNPq e FINEP pelo suporte financeiro para a realização deste projeto e a UFRGS e SATC pela estrutura utilizada na condução desta pesquisa.

\section{BIBLIOGRAFIA}

[1] GARCÍA-PLAZA E., NÚÑEZ P.J., SALGADO D.R., et al., "Surface Finish Monitoring in Taper Turning CNC Using Artificial Neural Network and Multiple Regression Methods", Procedia Engineering , v. 63, pp. $599-607,2013$.

[2] ULUTAN D., OZEL T., "Machining induced surface integrity in titanium and nickel alloys: A review", International Journal of Machine Tools \& Manufacture , v.51, pp. 250-280, 2011.

[3] CRUDU, M., FATU, A., HAJJAM, M., et al., "Numerical and experimental study of reciprocating rod seals including surface roughness effects", Sealing Technology, n.6, pp. 8-11, 2013.

[4] GUO Y.B., WARREN A.W., HASHIMOTO F., "The basic relationships between residual stress, white layer, and fatigue life of hard turned and ground surfaces in rolling contact", CIRP Journal of Manufacturing Science and Technology, v. 2, n.2, pp. 129-134, 2010.

[5] SCHWACH D. W., GUO Y.B., "A fundamental study on the impact of surface integrity by hard turning on rolling contact fatigue", International Journal of Fatigue, v. 28, pp. 1838-1844, 2006.

[6] BENARDOS P.G., VOSNIAKOS G.C., "Predicting surface roughness in machining: a review", International Journal of Machine Tools \& Manufacture, v.43, pp. 833-844, 2003.

[7] FERRARESI D., Fundamentos da usinagem dos metais, São Paulo, Editora blucher, 2013.

[8] BHOGAL S. S., SINDHU C., DHAMI S. S., et al., "Minimization of Surface Roughness and Tool Vibration in CNC Milling Operation", Journal of Optimization, 2015.

[9] TRENT E. M., WRIGHT P. K., Metal cutting, Boston, Butterworth-Heinemann, 2000.

[10] COLEMAN, D. E., MONTGOMERY D. C., "A Systematic Approach to Planning for a Designed Industrial Experiment (with Discussion)", Technometrics, v. 35, pp. 1-27, 1993.

[11] ASILTÜRK I., AKKUS H., "Determining the effect of cutting parameters on surface roughness in hard turning using the Taguchi method", Measurement, v. 44, pp. 1697-1704, 2011.

[12] MUÑOZ-ESCALONA P., CASSIER Z., "Influence of the critical cutting speed on the surface finish of turned steel", Wear, v. 218, pp.103-109, 1998.

[13] CAPELLO E., "Residual stresses in turning Part I: Influence of process parameters", Journal of Materials Processing Technology, v. 160, pp. 221-228, 2005. 
[14] CAPELLO E., "Residual stresses in turning Part II: Influence of the machined material", Journal of Materials Processing Technology, v. 172, pp. 319-326, 2006.

[15] SENTHILKUMAR N., TAMIZHARASAN T., "Effect of Tool Geometry in Turning AISI 1045 Steel: Experimental Investigation and FEM Analysis", Arab J Sci Eng.,v. 39, pp. 4963-4975, 2014.

[16] SASAHARA H., "The effect on fatigue life of residual stress and surface hardness resulting from different cutting conditions of $0.45 \% \mathrm{C}$ steel”, International Journal of Machine Tools \& Manufacture, v. 45, pp. 131-136, 2005.

[17] GUNNBERG F., ESCURSELL M., JACOBSON M., "The influence of cutting parameters on residual stresses and surface topography during hard turning of $18 \mathrm{MnCr} 5$ case carburised steel", Journal of Materials Processing Technology, v.174, pp. 82-90, 2006.

[18] CABRERA J. M., MOLINER R.T, DA SILVEIRA J. L. L., "The influence of cutting speed and feed rate in surface integrity of AISI 1045”, Ingeniería Mecánica, v. 18, n. 3, pp. 203-210, 2015.

[19] DAHLMAN P., GUNNBERG F., JACOBSON M., "The influence of rake angle, cutting feed and cutting depth on residual stresses in hard turning", Journal of materials processing technology, v.147, pp. 181184, 2004.

[20] WAECHTER V. D., Influência dos procedimentos de corte sobre as distribuições de tensões residuais em barras redondas trefiladas de aço ABNT 1045, Dissertação de M.Sc., UFRGS/PPGE3M, 2013.

[21] NUNES R. M., Estudo de distorção de barras cilíndricas de aço ABNT 1045 em uma rota de fabricação envolvendo trefilação combinada e têmpera por indução, Tese de D.Sc., UFRGS/PPGE3M, 2012.

[22] Ensino, CIMM, http://www.cimm.com.br/portal/material_didatico. Acessado em agosto de 2017.

[23] TANSEL I. N., ERKAL C., KERAMIDAS T., "The chaotic characteristics of three dimensional cutting", The International Journal of Machine Tools and Manufacture, v. 32, pp.811-827, 1992.

[24] SIDDHPURA M., PAUROBALLY R., "A review of chatter vibration research in turning", International journal of machine tools \& manufacture, v. 61, pp. 27-47, 2012.

\section{ORCID}

Guilherme Roberto dos Santos Biasibetti

Luiz Carlos de Cesaro Cavaler

Rafael Menezes Nunes

https://orcid.org/0000-0002-0670-6704

Alexandre da Silva Rocha

https://orcid.org/0000-0003-3097-3527

https://orcid.org/0000-0003-2435-8499

https://orcid.org/0000-0002-4086-5389 